\title{
GUIDELINE FOR THE MANAGEMENT OF BILE DUCT CANCERS BY THE BRAZILIAN GASTROINTESTINAL TUMOR GROUP
}

\author{
Rachel RIECHELMANN ${ }^{1,2}$, Anelisa K COUTINHO ${ }^{3}$, Rui F WESCHENFELDER ${ }^{4}$, \\ Gustavo ANDRADE DE PAULO ${ }^{1}$, Gustavo dos Santos FERNANDES ${ }^{5}$, Markus GIFONI \\ Maria de Lourdes OLIVEIRA ${ }^{7}$, Rene GANSL ${ }^{8}$, Roberto GIL $^{9}$, Gustavo LUERSEN ${ }^{4}$, \\ Lucio LUCAS $^{10}$, Marcio REISNER ${ }^{11}$, Fernando Meton VIEIRA ${ }^{12}$, \\ Marcel Autran MACHADO ${ }^{2}$, Andre MURAD $^{13}$, Alessandro OSVALDT ${ }^{14}$, \\ Miguel BRANDÃO ${ }^{3}$, Elisangela CARVALHO ${ }^{15}$, Tulio SOUZA ${ }^{16}$, Tulio PFIFFER ${ }^{1}$ and \\ Gabriel PROLLA ${ }^{17}$
}

Received 18/6/2015 Accepted 22/9/2015

\begin{abstract}
The Brazilian Gastrointestinal Tumor Group developed guidelines for the surgical and clinical management of patients with billiary cancers. The multidisciplinary panel was composed of experts in the field of radiology, medical oncology, surgical oncology, radiotherapy, endoscopy and pathology. The panel utilized the most recent literature to develop a series of evidence-based recommendations on different treatment and diagnostic strategies for cholangiocarcinomas and gallbladder cancers.

HEADINGS - Bile duct neoplasms. Cholangiocarcinoma. Therapeutics. Practice guidelines as topic. Consensus.
\end{abstract}

\section{INTRODUCTION}

Malignant neoplasms of the biliary tract include gallbladder cancer, intrahepatic and extrahepatic (proximal and distal) cholangiocarcinoma and cancer of the duodenal papilla (ampulla of Vater). They form a relatively rare group of tumors with an estimated 10,310 new cases of gallbladder cancer or cholangiocarcinoma in the United States in 2014 ${ }^{(38)}$.

The disease is usually diagnosed only in its late stages after the onset of related symptoms because of the absence of established preventive and/or screening programs. This explains the high levels of mortality associated with biliary tract cancer ${ }^{(38)}$.

\section{OBJECTIVE}

This report is an initiative of the Brazilian Gastrointestinal Tumors Group(GTG) to bring together the opinion of Brazilian experts based on their extensive discussion of the current scientific evidence of the diagnosis, staging and treatment of biliary tract cancers.

\section{METHODS}

This article sets out the considerations of Brazilian experts from various specialties, including radiology, pathology, gastroenterology, digestive surgery, cancer surgery, radiation and medical oncology. The panel included experts from several regions of Brazil. All topics for discussion were previously selected and distributed among the panel members. The presentations and voting of experts occurred during face to face meetings and conference calls. A search of the medical literature related to selected subjects was performed using MEDLINE (National Library of Medicine). The scientific evidence and recommendations were classified according to Figures 1 and 2 . In the absence of sufficient evidence to build a clear conclusion, final recommendations were based on the majority of panel experts' opinion. All discussions and recommendations considered the TNM Staging of the AJCC 7th edition from 2010.

\footnotetext{
Declared conflict of interest of all authors: none

Disclosure of funding: no funding received

${ }^{1}$ Instituto do Câncer do Estado de São Paulo, São Paulo, SP, Brasil; ${ }^{2}$ Hospital Sírio Libanês, São Paulo, SP, Brasil; ${ }^{3}$ Clínica AMO, Salvador, BA, Brasil; ${ }^{4}$ Hospital Moinhos de Vento, Porto Alegre RS, Brasil. 5 Oncologia, Hospital Sírio Libanês, Brasília, DF, Brasil, ${ }^{6}$ Clínica Fujiday Oncologia, Fortaleza, CE, Brasil; 7 Oncologia D’Or, Rio de Janeiro, RJ, Brasil; ${ }^{8}$ Centro Paulista de Oncologia, São Paulo, SP, Brasil; ${ }^{9}$ Instituto Nacional do Câncer, Rio de Janeiro, RJ, Brasil; ${ }^{10}$ Hospital de Base, Brasília, DF, Brasil; ${ }^{1}$ Universidade Federal do Rio de Janeiro, Rio de Janeiro, RJ, Brasil; ${ }^{12}$ Instituto COI de Pesquisa, Educação e Gestão, Rio de Janeiro, RJ, Brasil; ${ }^{13}$ Hospital das Clínicas da Universidade Federal de Minas Gerais, Belo Horizonte, MG. Brasil; ${ }^{14}$ Hospital de Clínicas, Porto Alegre, RS, Brasil; ${ }^{15}$ Hospital Português, Salvador, BA, Brasil; 16 Hospital Aliança, Salvador, BA, Brasil; ${ }^{17}$ Hospital Mãe de Deus, Porto Alegre, RS, Brasil.

Correspondence: Rachel Riechelmann. Av. Dr. Arnaldo, 251, $12^{\circ}$ andar, Pesquisa Clínica. CEP: 01246-000 - São Paulo, SP, Brasil. E-mail: rachel.riechelmann@hc.fm.usp.br
} 
I - From at least one large randomized controlled trial (RCT) of good methodological quality (low potential for bias) or meta-analysis of randomized controlled trials and conducted with no heterogeneity.

II - Small RCTs or large RCTs with suspected bias (low methodological quality) or meta-analysis of these trials or trials with demonstrated heterogeneity.

III - Prospective cohort studies.

IV - Retrospective cohort studies or case-control studies.

V - Studies without a control group, case reports, expert opinions.

FIGURE 1. Level of evidence (LE) - CDC Grading System

A - Solid evidence of efficacy with substantial clinical benefit, strongly recommended.

B - Strong or moderate evidence in terms of efficacy, but with a limited clinical benefit, usually recommended.

C - Insufficient evidence of efficacy or the benefit does not outweigh the risk / disadvantages (adverse events, costs etc.), optional.

D - Moderate evidence against the efficacy or evidence indicating an adverse outcome, generally not recommended.

E - Strong evidence against the efficacy or indicating an adverse outcome, not recommended.

FIGURE 2. Strength of recommendations (SR) - Classification system CDC

\section{What tests have a diagnostic role in malignant neo- plasms of the biliary tract?}

Definitive diagnosis of biliary tract cancer occurs preferably after surgery as a result of pathology tests. However, diagnosis is equally necessary in situations where no such procedure is indicated, for example, in the cases of advanced disease where surgery is not indicated.

\section{Endoscopic retrograde cholangiopancreatography (ERCP)}

ERCP allows diagnosis by collecting material (bile or brushed) for cytology or biopsy and has a role in diagnosing cholangiocarcinoma, and identifying patients ineligible for surgery. LE: II - SR: B.

\section{Upper GI Endoscopy (UGIE)}

Endoscopy with biopsy also has a diagnostic indication for malignancies of the duodenal papilla. LE: II - SR: A.

\section{Endoscopic ultrasound (EUS)}

EUS guided biopsy can be used for diagnosis, especially of distal cholangiocarcinoma and duodenal bulb cancer. The technique allows access to primary tumors and regional lymph nodes. LE: III - SR: B.

There is no indication for EUS guided biopsy in either hilar or intrahepatic cholangiocarcinoma LE: III - SR: D.

\section{Cholangioscopy}

Cholangioscopy may help visualize suspicious lesions and perform biopsies of the distal bile duct. However, patient access to this test remains limited to a few centers. LE: V, R: C.

\section{Which imaging tests should be used for the staging of biliary tract cancers?}

Patients with an incidental finding of gallbladder adenocarcinoma after laparoscopic examination and who have pathologic stage T1a with negative margins do not require investigation with imaging. From stage Tla pathologic stage investigation with imaging should be carried out. LE: III - SR: B.

Total abdomen magnetic resonance imaging (MRI) with contrast associated with magnetic resonance cholangiopancreatography (MRCP) is considered the gold standard for the staging of malignant neoplasms of the biliary tract - LE: II - SR: A.

In cases where abdominal MRI associated with CPRM is not available, a total abdominal computed tomography (CT) scan with contrast is indicated. LE: II - SR: A

The abdominal imaging test for staging purposes should occur prior to biliary tract drainage to prevent post-drainage alterations obstructing the neoplastic assessments.

Chest CT should also be added for staging - LE: V - SR: B.

The EUS, if available, may be useful in staging the primary tumor and regional lymph nodes, especially in cases of distal cholangiocarcinoma, gallbladder adenocarcinoma - LE: III-SR: B, and ampullary malignanciesLE: III - SR: C.

The value of PET-CT in staging is still uncertain and therefore optional if available-LE: III - SR: C.

\section{Which tumor markers can be used in biliary tract cancer?}

The assessment of tumor markers such as carcinoembryonic antigen (CEA) and $\mathrm{Ca} 19.9$ can be useful in the diagnosis of biliary tract cancer and is considered optional - LE: IV - SR: C.

Tumor markers should be assessed carefully prior to surgery because cholestasis may overestimate levels.

Assessment of $\mathrm{Ca} 19.9$ is indicated for prognosis and response - LE: IV- SR: B but CEA assessment is optional - LE: IV - SR: C.

\section{Should laparoscopy be used routinely in the staging of cancer of the biliary tract?}

Laparoscopy is optional in the staging of biliary tract cancer, but may be considered for patients with signs of locally advanced disease in order to exclude metastatic disease - LE: III - SR: C. 


\section{What is the role of ERCP in the palliative treatment of cholangiocarcinoma?}

ERCP for palliative treatment is indicated, allowing the unblocking of an obstructed biliary tract by using metal or plastic prostheses - LE: I - SR: A.

\section{What are the minimum elements that should be described in the pathology report of cancer of the biliary tract?}

The surgical specimen must contain information regarding resected segments, as well as size and weight.

For the description of a tumor, the pathological report must contain:

- location;

- size;

- number of tumors (with special attention to the intrahepatic colangicarcinoma);

- the growth pattern (mass-forming type, infiltrative periductal or mixed);

- histological type and subtype (adenocarcinoma intestinal type, pancreatobiliary or papillary);

- differentiation (well differentiated, moderately differentiated, poorly differentiated or undifferentiated);

- tumor extension;

- surgical margins;

- angiolymphatic invasion (whether present or absent);

- perineural invasion (whether present or absent);

- associated diseases (cirrhosis, cholangitis, hepatitis, gallstones and others), and

- TNM staging.

Negative surgical margins should mention the shortest distance; when positive, it must report which margins. Attention should also be given to the component of the margin, if invasive or in situ. Negative surgical margins are considered those with more than $1 \mathrm{~cm}$, or if microscopic, larger than $0.1 \mathrm{~cm}$.

Immunohistochemistry (IHC) is important in differentiating cancer of biliary lesions from benign or metastatic lesions. ICH also allows the differentiation of adenocarcinoma of the duodenal papilla in intestinal or pancreaticobiliary subtypes. The ICH panel must contain the following markers: CK7, CK20, CDX2, CK19, CEA and $\mathrm{Ca} 19.9$.

The assessment of microsatellite instability (MLH1, MSH2, MSH6 and PMS2) and prognostic factors (MUC, ciclinaD1, P16, P53, pRb and others) is optional.

Proper macroscopic processing of the surgical specimen is essential for adequate evaluation of margins. One of the most difficult and important margins is in the pancreatic duct. For processing purposes, the distal end of the main pancreatic duct margin should be dyed by making cuts longitudinal to the main pancreatic duct, and collecting samples for histological study of the duct and the dyed side. Thus, evaluation of the margin and its distance to the tumor or ductal epithelial dysplasia are easily measured.

\section{What are the principles of surgical oncology in cancer of the biliary tract?}

Complete surgical resection with negative margins is the only potentially curative treatment for patients with localized cancer of the biliary tract.

Clipping to facilitate adjuvant radiotherapy is optional and must be conducted in institutions that adopt this adjuvant treatment as routine - LE: V - SR: C.

Embolization techniques to increase the residual liver segment may be used if necessary.

Laparoscopic surgery allows surgical staging, hepatectomy, lymphadenectomy, and production of liver jejunal anastomosis. Thus it is optional - LE: V - SR: C.

\section{Incidental finding of gallbladder cancer}

The diagnosis of gallbladder cancer, as an incidental finding in post cholecystectomy, with the pathological Tis or T1a, does not require additional surgery and the patient should only be monitored - LE: III - SR: B.

Patients with pathologic stage $\mathrm{T} 1 \mathrm{~b}$ should be reoperated with hepatectomy of segments IVb and $\mathrm{V}$ and radical lymphadenectomy in order to have clear margins - LE: IV - SR: A.

Resection of the biliary tract is not indicated if it is not affected - LE: IV - SR: D.

Restaging with imaging tests may be necessary before reoperation in cases of gallbladder cancer with incidental finding in order to avoid surgery in cases of advanced disease. Reoperation is indicated in these cases, if the patient has completed the initial diagnostic intervention within 6 months - LE: V - SR: B.

\section{Gallbladder}

A patient diagnosed with T1a gallbladder cancer should be treated only with cholecystectomy - LE: III - SR: $\mathrm{B}^{(25)}$.

For other stages that have the possibility of curative surgery, the optimal procedure consists of cholecystectomy with limited hepatectomy (segments IVb and V) and portal lymphadenectomy - LE: III - SR: $\mathrm{A}^{(10,17,37)}$.

Other liver segments and bile duct resection may be required to obtain negative margins.

\section{Hilar cholangiocarcinoma}

The standard procedure is radical surgical resection, including withdrawal of the extrahepatic biliary tract, extended en bloc hepatectomy, lymphadenectomy and reconstruction of the vascular and biliary tree aiming to obtain negative margins - LE: III - SR: $\mathrm{B}^{(5,6,41,42)}$.

\section{Distal cholangiocarcinoma}

The indicated surgical procedure is pancreaticoduodenectomy, aiming to obtain negative margins - LE: III - SR: $\mathrm{B}^{(27)}$.

\section{Ampulla of Vater}

Whipple surgery is the treatment of choice in cases of cancer of the duodenal papilla with localized disease considered resectable - LE: IV - SR: B. 


\section{Intrahepatic cholangiocarcinoma}

The standard surgery for patients with intrahepatic cholangiocarcinoma is hepatectomy obtaining negative margins - LE: III - SR: $B^{(22,24,33)}$. Portal lymphadenectomy should be considered - LE: IV - SR: $\mathrm{C}^{(7,36)}$.

\section{Liver transplantation}

Liver transplantation is indicated for hilar cholangiocarcinoma, although few centers worldwide would perform this procedure in this disease. Selected cases of hilar cholangiocarcinoma may be considered for liver transplantation if they meet the following criteria: localized disease, preferably sclerosing cholangitis with malignancy and negative lymph nodes - LE: IV - SR: B. In Brazil, this procedure is not yet approved for this indication by the Ministry of Health ${ }^{(3,8,12,15,18,32)}$.

\section{Adjuvant treatment}

Adjuvant studies in biliary tract cancer are mostly based on small numbers of patients, retrospective, and involving heterogeneous populations which report conflicting results. However, due to the high risk of recurrence after surgery, patients diagnosed with cancer of the biliary tract may be considered for adjuvant treatment with chemotherapy and/ or radiotherapy ${ }^{(4)}$. LE: IV - SR: C.

Adjuvant treatment can be offered both for patients with positive surgical margins - LE: IV - SR: B and for patients with negative surgical margins - LE: IV - SR: C.

If used, chemotherapy and radiotherapy should be based on fluoropyrimidines. Adjuvant chemotherapy should use platinum-based regimens and gemcitabine (accepted due to extrapolation of metastatic disease).

Adjuvant chemotherapy with 5-fluorouracil (5FU) and radiotherapy has been shown to improve survival in a retrospective study conducted by the Mayo Clinic ${ }^{(14)}$.

A case-control study conducted in Korea with 120 patients, offered chemotherapy combined with radiotherapy followed by chemotherapy or chemotherapy associated with isolated radiotherapy. The chemotherapy of choice was the $5 \mathrm{FU}$. The progression-free survival (PFS) at 3 years was $26.6 \%$ versus $45.2 \%(P=0: 04)$ and overall survival (OS) at 3 years was 30.8 versus $62.6(P<0.01)$, with benefit for the group of chemotherapy associated with radiotherapy followed by chemotherapy ${ }^{(26)}$.

The recent series of MDACC with 157 operated patients with gallbladder or cholangiocarcinoma cancer and free microscopic margins of cancer, showed no benefit in overall survival at 5 years in patients that received adjuvant chemotherapy or chemoradiotherapy ${ }^{(13)}$.

A phase III study conducted in Japan randomized 508 patients diagnosed with pancreatic or biliary tract cancer (cholangiocarcinoma 139 and 140 gallbladder cancer) surgically treated for adjuvant chemotherapy treatment with 5FU and mitomycin or observation. Subgroup analysis of patients with gallbladder cancer showed $26 \%$ overall survival at 5 years in the adjuvant chemotherapy group versus $14.4 \%$ for the observation group $(P=0.0367)$, and $20.3 \%$ of PFS at 5 years in the chemotherapy group versus $11.6 \%$ in the control group $(P=0.021)^{(39)}$. This benefit was statistically significant only in patients with non-curative resection (positive margins). There was no benefit for adjuvant treatment in this study in other tumor sites (pancreas, ampulla of Vater and biliary duct).

A meta-analysis of published data, with 4915 patients treated with surgery alone versus 1797 treated with surgery followed by adjuvant treatment (chemotherapy and/or radiotherapy), suggested survival gain with adjuvant treatment (HR $0.74 P 0: 06)^{(16)}$. Treatment with chemotherapy or chemoradiotherapy was better than adjuvant radiotherapy alone. The greatest benefits related to adjuvant therapy occurred in patients with margins or positive lymph nodes ${ }^{(16)}$.

For patients with tumors of the ampulla of Vater, the phase III study ESPAC-3 ${ }^{(30)}$ showed no significant gain in survival with the addition of adjuvant chemotherapy with $5 \mathrm{FU}$ and leucovorin $(\mathrm{Lv})$ or gemcitabine.

\section{What is the best systemic treatment in the first line for metastatic cancer of the biliary tract?}

The first-line treatment for metastatic biliary tract cancer should be cisplatin and gemcitabine - LE: I - SR: A.

The replacement of cisplatin with oxaliplatin in combination with gemcitabine is a valid option - LE I-SR: $\mathrm{C}^{(35)}$.

In subsequent therapeutic lines, if the patients' performance allows, chemotherapy with fluoropirirmidinas, taxanes or irinotecan can be used - LE: III - SR: C (there was no consensus among the members of this multidisciplinary panel).

The use of targeted therapy in this setting is not indicated, except in the context of investigational protocols LE: II - SR: E.

There are several phase II studies with different chemotherapy protocols, but with heterogeneous groups and limited numbers of patients ${ }^{(1,2,6,9,11,19,20,21,23,28,29,31,32,34,35)}$.

A study published in 2010 randomized patients with gallbladder adenocarcinoma in groups of palliative supportive care, chemotherapy with 5FU combined with leucovorin or gemcitabine associated with oxaliplatin (GEMOX). The group receiving chemotherapy with the GEMOX scheme had better overall survival (4.5 versus 4.6 versus 9.5 months respectively $P=0.039)^{(35)}$.

The landmark ABC-02 phase III trial randomized 410 patients with inoperable biliary tract cancer to receive systemic treatment with gemcitabine with or without cisplatin. There was a benefit in overall survival favoring multidrug therapy (HR $0.64-8.1$ vs 11.7 months $P<0.001)^{(40)}$.

\section{Follow up after treatment with curative intent}

Follow up should be clinical history and physical examination every 6 months for 2 years - LE: V - SR: B.

Performing abdominal imaging studies (CT or MRI) every 6 months for 2 years, and tumor markers CEA and CA19.9 with the same frequency are optional - LE: V - SR: C.

\section{CONCLUSION}

Malignant neoplasms of the biliary tract comprise a spectrum of different tumors with particular characteristics. The oncologic management of this entity should be based on the multidisciplinary assessment and on existing scientific evidence. 
Riechelmann R, Coutinho AK, Weschenfelder RF, Andrade de Paulo G, Fernandes GS, Gifoni M, Oliveira ML, Gansl R, Gil R, Luersen G, Lucas L, Reisner M, Viera FM, Machado MA, Murad A, Osvaldt A, Brandão M, Carvalho E, Souza T, Pfiffer T, Prolla G. Consenso sobre o manejo de tumores de vias biliares pelo Grupo Brasileiro de Tumores Gastrointestinais. Arq Gastroenterol. 2016,53(1):5-9.

RESUMO - O Grupo Brasileiro de Tumores Gastrointestinais desenvolveu diretrizes de tratamento cirúrgico e clínico de pacientes com tumores de vias biliares. O painel multidisciplinar foi composto de especialistas nas áreas radiologia, oncologia, cirurgia, radioterapia, endoscopia e anatomia patológica. O painel utilizou literatura atual para desenvolver recomendações baseadas em evidência científica para as diferentes estratégias terapêuticas e diagnósticas dos colangiocarcinomas e tumores de vesícula biliar.

DESCRITORES - Neoplasias dos ductos biliares. Colangiocarcinoma. Terapêutica. Guias de prática clínica como assunto. Consenso.

\section{REFERENCES}

1. Alberts SR, Al-Khatib H, Mahoney MR, Burgart L, Cera PJ, Flynn PJ, et al. Gemcitabine, 5-fluorouracil, and leucovorin in advanced biliary tract and gallbladder carcinoma: a North Central Cancer Treatment Group phase II trial. Cancer. 2005; 103:111-8.

2. André T, Reyes-Vidal JM, Fartoux L, Ross P, Leslie M, Rosmorduc O, et al Gemcitabine and oxaliplatin in advanced biliary tract carcinoma: a phase II study. Br J Cancer. 2008;99:862-7.

3. Becker NS, Rodriguez JA, Barshes NR, O’Mahony CA, Goss JA, Aloia TA. Outcomes analysis for 280 patients with cholangiocarcinoma treated with liver transplantation over an 18-year period. J Gastrointest Surg. 2008;12:117-22.

4. Cereda S, Belli C, Reni M. Adjuvant treatment in biliary tract cancer: to treat or not to treat? World J Gastroenterol. 2012;18:2591-6.

5. Cheng QB, Yi B, Wang JH, Jiang XQ, Luo XJ, Liu C, et al. Resection with tota caudate lobectomy confers survival benefit in hilar cholangiocarcinoma of Bismuth type III and IV. Eur J Surg Oncol. 2012;38:1197-203.

6. Cho JY, Paik YH, Chang YS, Lee SJ, Lee DK, Song SY, et al. Capecitabine combined with gemcitabine (CapGem) as first-line treatment in patients with advanced/ metastatic biliary tract carcinoma. Cancer. 2005;104:2753-8.

7. Clark CJ, Wood-Wentz CM, Reid-Lombardo KM, Kendrick ML, Huebne M, Que FG. Lymphadenectomy in the staging and treatment of intrahepatic cholangiocarcinoma: a population-based study using the National Cancer Institute SEER database. HPB (Oxford). 2011;13:612-20.

8. Darwish Murad S, Kim WR, Harnois DM, Douglas DD, Burton J, et al. Efficacy of neoadjuvant chemoradiation, followed by liver transplantation, for perihilar cholangiocarcinoma at 12 US centers. Gastroenterology. 2012;143:88-98.

9. Doval DC, Sekhon JS, Gupta SK, Fuloria J, Shukla VK, Gupta S, et al. A phase II study of gemcitabine and cisplatin in chemotherapy-naive, unresectable gall bladder cancer. Br J Cancer 2004;90:1516-20.

10. Downing SR, Cadogan KA, Ortega G, Oyetunji TA, Siram SM, Chang DC, et al. Early-stage gallbladder cancer in the Surveillance, Epidemiology, and End Results database: effect of extended surgical resection. Arch Surg. 2011;146:734-8.

11. Ducreux M, Van Cutsem E, Van Laethem JL, Gress TM, Jeziorski K, Rougier P, et al. EORTC Gastro Intestinal Tract Cancer Group. A randomised phase II trial of weekly high-dose 5-fluorouracil with and without folinic acid and cisplatin in patients with advanced biliary tract carcinoma: results of the 40955 EORTC trial Eur J Cancer. 2005;41:398-403.

12. Duignan S, Maguire D, Ravichand CS, Geoghegan J, Hoti E, Fennelly D, et al. Neoadjuvant chemoradiotherapy followed by liver transplantation for unresectable cholangiocarcinoma: a single-centre national experience. HPB (Oxford). 2014;16:91-8

13. Glazer ES, Liu P, Abdalla EK, Vauthey JN, Curley SA. Neither neoadjuvant nor adjuvant therapy increases survival after biliary tract cancer resection with wide negative margins. J Gastrointest Surg. 2012;16:1666-71.

14. Gold DG, Miller RC, Haddock MG, Gunderson LL, Quevedo F, Donohue JH, et al. Adjuvant therapy for gallbladder carcinoma: the Mayo Clinic Experience. Int J Radiat Oncol Biol Phys. 2009;75:150-5.

15. Hong JC, Jones CM, Duffy JP, Petrowsky H, Farmer DG, French S, et al Comparative analysis of resection and liver transplantation for intrahepatic and hilar cholangiocarcinoma: a 24-year experience in a single center. Arch Surg. 2011;146:683-9.

16. Horgan AM, Amir E, Walter T, Knox JJ. Adjuvant therapy in the treatment of biliary tract cancer: a systematic review and meta-analysis. J Clin Oncol. 2012;30:1934-40

17. Jensen EH, Abraham A, Habermann EB, Al-Refaie WB, Vickers SM, Virnig BA, et al. A critical analysis of the surgical management of early-stage gallbladder cancer in the United States. J Gastrointest Surg. 2009;13:722-7.

18. Kaiser GM, Sotiropoulos GC, Jauch KW, Löhe F, Hirner A, Kalff JC, et al. Liver transplantation for hilar cholangiocarcinoma: a German survey. Transplant Proc. 2008;40:3191-3

19. Kim HJ, Lee NS, Lee SC, Bae SB, Kim CK, Cheon YG, et al. A phase II study of gemcitabine in combination with oxaliplatin as first-line chemotherapy in patients with inoperable biliary tract cancer. Cancer Chemother Pharmacol. 2009;64:371-7.

20. Kim TW, Chang HM, Kang HJ, Lee JR, Ryu MH, Ahn JH, et al. Phase II study of capecitabine plus cisplatin as first-line chemotherapy in advanced biliary cancer. Ann Oncol. 2003;14:1115-20.

21. Knox JJ, Hedley D, Oza A, Feld R, Siu LL, Chen E, et al. Combining gemcitabine and capecitabine in patients with advanced biliary cancer: a phase II trial. J Clin Oncol. 2005;23:2332-8.
22. Konstadoulakis MM, Roayaie S, Gomatos IP, Labow D, Fiel MI, Miller CM, et al. Fifteen-year, single-center experience with the surgical management of intrahepatic cholangiocarcinoma: operative results and long-term outcome. Surgery. 2008;143:366-74

23. Kornek GV, Schuell B, Laengle F, Gruenberger T, Penz M, Karall K, et al. Mitomycin $\mathrm{C}$ in combination with capecitabine or biweekly high-dose gemcitabine in patients with advanced biliary tract cancer: a randomised phase II trial. Ann Oncol. 2004; 15:478-83.

24. Lang H, Sotiropoulos GC, Sgourakis G, Schmitz KJ, Paul A, Hilgard P, et al Operations for intrahepatic cholangiocarcinoma: single-institution experience of 158 patients. J Am Coll Surg. 2009;208:218-28.

25. Lee SE, Jang JY, Lim CS, Kang MJ, Kim SW. Systematic review on the surgica treatment for T1 gallbladder cancer. World J Gastroenterol. 2011;17:174-80.

26. Lim KH, Oh DY, Chie EK, Jang JY, Im SA, Kim TY, et al. Adjuvant concurrent chemoradiation therapy (CCRT) alone versus CCRT followed by adjuvan chemotherapy: which is better in patients with radically resected extrahepatic biliary tract cancer?: a non-randomized, single center study. BMC Cancer. 2009;9:345.

27. Nagorney DM, Donohue JH, Farnell MB, Schleck CD, Ilstrup DM. Outcomes after curative resections of cholangiocarcinoma. Arch Surg. 1993;128:871-7.

28. Nehls O, Klump B, Arkenau HT, Hass HG, Greschniok A, Gregor M, et al. Oxaliplatin, fluorouracil and leucovorin for advanced biliary system adenocarcinomas: a prospective phase II trial. Br J Cancer. 2002;87:702-4.

29. Nehls O, Oettle H, Hartmann JT, Hofheinz RD, Hass HG, Horger MS, et al Capecitabine plus oxaliplatin as first-line treatment in patients with advanced biliary system adenocarcinoma: a prospective multicentre phase II trial. Br J Cancer. 2008;98:309-15.

30. Neoptolemos JP, Moore MJ, Cox TF, Valle JW, Palmer DH, McDonald AC, et al European Study Group for Pancreatic Cancer. Effect of adjuvant chemotherapy with fluorouracil plus folinic acid or gemcitabine vs observation on survival in patients with resected periampullary adenocarcinoma: the ESPAC-3 periampullary cancer randomized trial. JAMA. 2012;308:147-56.

31. Okusaka T, Nakachi K, Fukutomi A, Mizuno N, Ohkawa S, Funakoshi A, et al Gemcitabine alone or in combination with cisplatin in patients with biliary tract cancer: a comparative multicentre study in Japan. Br J Cancer. 2010;103:469-74.

32. Rea DJ, Heimbach JK, Rosen CB, Haddock MG, Alberts SR, Kremers WK, et al. Liver transplantation with neoadjuvant chemoradiation is more effective than resection for hilar cholangiocarcinoma. Ann Surg. 2005;242:451-8.

33. Ribero D, Pinna AD, Guglielmi A, Ponti A, Nuzzo G, Giulini SM, et al. Italian Intrahepatic Cholangiocarcinoma Study Group. Surgical Approach for Long-term Survival of Patients With Intrahepatic Cholangiocarcinoma: A Multi-institutional Analysis of 434 Patients. Arch Surg. 2012;147:1107-13.

34. Riechelmann RP, Townsley CA, Chin SN, Pond GR, Knox JJ. Expanded phase II trial of gemcitabine and capecitabine for advanced biliary cancer. Cancer. 2007:110:1307-12.

35. Sharma A, Dwary AD, Mohanti BK, Deo SV, Pal S, Sreenivas V, et al. Bes supportive care compared with chemotherapy for unresectable gall bladder cancer: a randomized controlled study. J Clin Oncol. 2010;28:4581-6.

36. Shimada M, Yamashita Y, Aishima S, Shirabe K, Takenaka K, Sugimachi K. Value of lymph node dissection during resection of intrahepatic cholangiocarcinoma. $\mathrm{Br}$ J Surg. 2001;88:1463-6

37. Shirai Y, Sakata J, Wakai T, Ohashi T, Hatakeyama K. "Extended" radical cholecystectomy for gallbladder cancer: long-term outcomes, indications and limitations. World J Gastroenterol. 2012;18:4736-43.

38. Siegel R, Ma J, Zou Z, Jemal A. Cancer statistics, 2014. CA Cancer J Clin. 2014;64:9-29.

39. Takada T, Amano H, Yasuda H, Nimura Y, Matsushiro T, Kato H, et al. Study Group of Surgical Adjuvant Therapy for Carcinomas of the Pancreas and Biliary Tract. Is postoperative adjuvant chemotherapy useful for gallbladder carcinoma? A phase III multicenter prospective randomized controlled trial in patients with resected pancreaticobiliary carcinoma. Cancer. 2002;95:1685-95

40. Valle J, Wasan H, Palmer DH, Cunningham D, Anthoney A, Maraveyas A, et al ABC-02 Trial Investigators. Cisplatin plus gemcitabine versus gemcitabine for biliary tract cancer. N Engl J Med. 2010;362:1273-81.

41. Van Gulik TM, Kloek JJ, Ruys AT, Busch OR, van Tienhoven GJ, Lameris JS et al. Multidisciplinary management of hilar cholangiocarcinoma (Klatskin tumor): extended resection is associated with improved survival. Eur J Surg Oncol. 2011:37:65-71

42. Wu XS, Dong P, Gu J, Li ML, Wu WG, Lu JH, et al. Combined portal vein resection for hilar cholangiocarcinoma: a meta-analysis of comparative studies. J Gastrointest Surg. 2013;17:1107-15. 